\title{
Magnetic Controlled Growth Rods in the Treatment of Scoliosis: Safety, Efficacy and Patient Selection
}

This article was published in the following Dove Press journal:

Medical Devices: Evidence and Research

\section{Athanasios I Tsirikos (D) Simon B Roberts \\ Scottish National Spine Deformity Center, Royal Hospital for Sick Children, University of Edinburgh, Edinburgh, UK}

\begin{abstract}
Early-onset scoliosis is defined as a spinal curvature greater than $10^{\circ}$ in children prior to 10 years of age. Untreated EOS may lead to progressively severe spinal deformity, impaired pulmonary development, restrictive lung disease, and both increased morbidity and mortality. Limitations of established conservative treatments include inability to correct severe deformity, as well as challenges with compliance when casting and bracing is applied. In addition, surgical treatment in the form of traditional growing rods requires regular surgical lengthenings and is associated with complications inherent with repeated invasive procedures and exposure to general anesthesia. MAGEC is an evolving magnetically controlled growing rod system for the treatment of EOS. After initial implantation, lengthening is achieved non-invasively by using magnetic external remote control. MAGEC offers the potential to control moderate and severe EOS, while avoiding repeated surgical procedures and associated complications. In this review, we examine the results from clinical, radiological and explant studies following the use of MAGEC, in the context of other established and emerging treatments for EOS.
\end{abstract}

Keywords: MAGEC, growth rods, early-onset, scoliosis, treatment

\section{Introduction}

Early-onset scoliosis (EOS) is defined as a spinal curvature greater than $10^{\circ}$ in the coronal plane with onset before 10 years of age. ${ }^{1}$ EOS may result from idiopathic, neuromuscular, congenital, syndromic, or thoracogenic aetiologies. ${ }^{2}$ The spine grows most rapidly in the first 5 years of life and during the adolescent growth spurt. $^{3}$ The number of alveoli and thoracic volume also increase most rapidly in the first 4 years and during adolescence. ${ }^{3}$ Untreated EOS may lead to thoracic insufficiency syndrome (TIS) and is associated with more than twofold increase in mortality by age 40 compared to the general population. ${ }^{4,5}$

Bracing and casting may be used to prevent curve progression in EOS while the child grows; serial casting is most effective for treating infantile idiopathic scoliosis and may delay surgical treatment for non-idiopathic EOS. ${ }^{6-9}$ The aim of surgery for EOS is to correct spinal deformity, support remaining growth of the spine and thoracic cavity, and improve patients' quality of life when non-operative methods are unsuccessful due to the severity and progressive nature of the deformity.

Harrington first described surgical distraction without fusion to treat spinal deformity. ${ }^{10}$ Moe et al subsequently reported a modification of Harrington's technique, limiting the subperiosteal exposure to the sites of spinal fixation with the rod passed
Correspondence: Athanasios I Tsirikos Scottish National Spine Deformity Center, Royal Hospital for Sick Children, Sciennes Road, Edinburgh EH9 ILF, UK Email atsirikos@hotmail.com 
subcutaneously. ${ }^{11}$ Blakemore et al described a further development of this technique with a single rod passed submuscularly, but still permitting sufficient rod contouring. ${ }^{12}$ Curve correction of $29-30 \%$ has been reported at final follow-up using these techniques with an overall $24 \%$ complication rate. $^{12,13} \mathrm{~A}$ single rod can be attached on the concave side of the curve, or rods can be attached to both the concave and convex aspects of the spine (dual rods). ${ }^{14}$ Dual growing rods may provide improved correction and stability. ${ }^{15}$ These traditional growing rods (TGR) are lengthened every 6 months by an invasive surgical procedure under general anesthesia (Figures 1 and 2). Concerns remain regarding high rates of
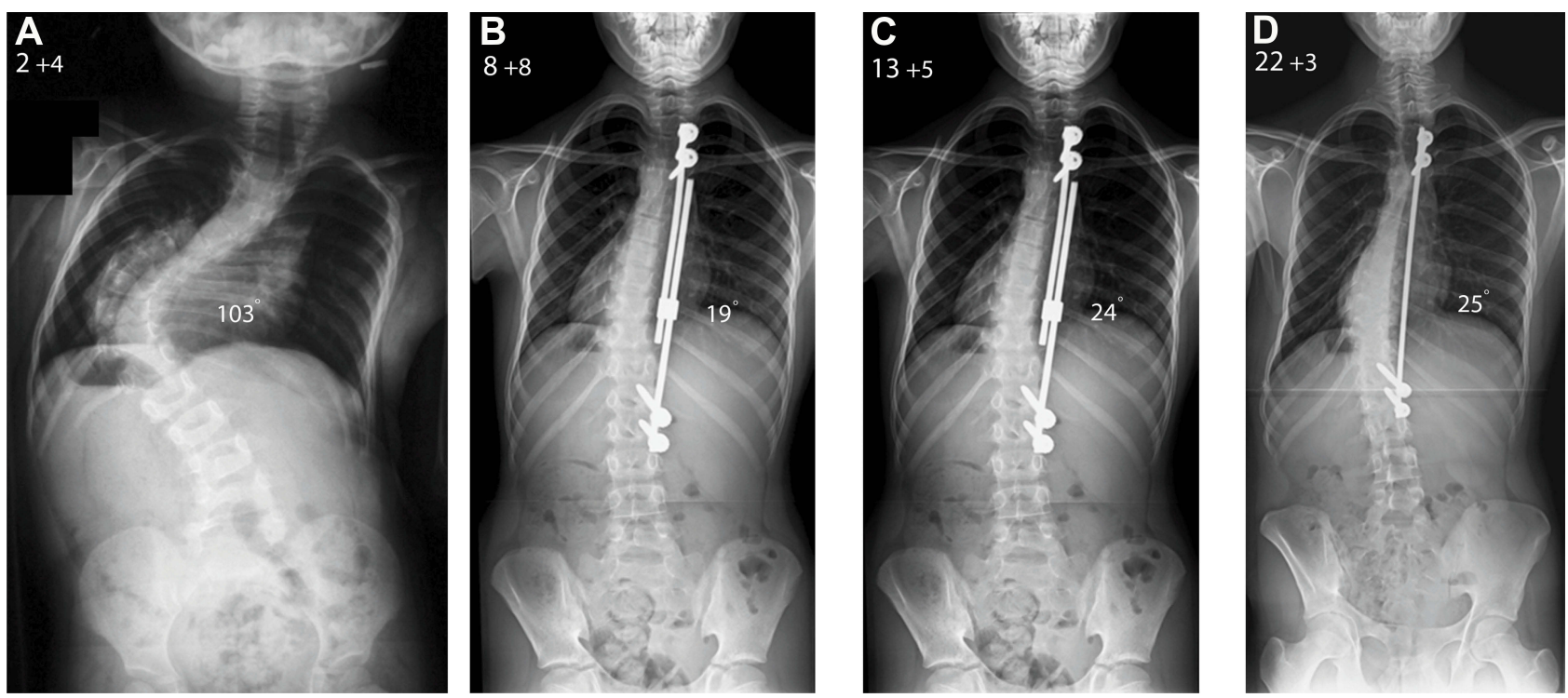

Figure I Male patient aged 2 years and 4 months with a very severe infantile idiopathic thoracic scoliosis (patient I; (A). The patient was treated with TGRs which were inserted at age 2.5 years. Repeat lengthenings were performed every 6 months and controlled the coronal deformity until the age of I3.5 years (B, C) when the patient underwent the definitive posterior spinal fusion. The distal rod of the construct had to be exchanged twice due to breakage and this was performed during planned lengthening procedures. At final follow-up aged 22 years and 3 months, the patient had a balanced spine with good correction of the scoliotic deformity (D).
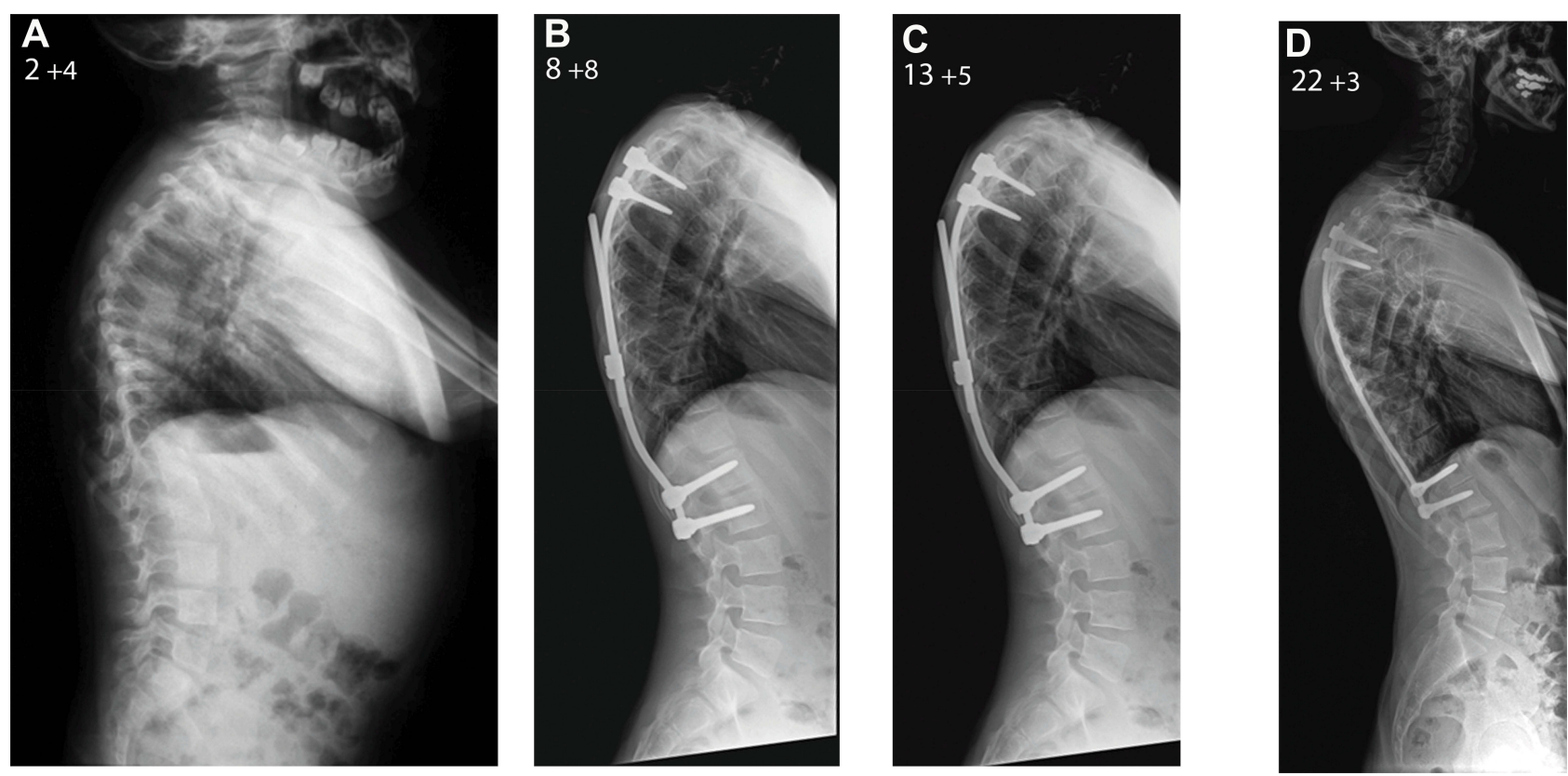

Figure 2 Lateral x-rays of the spine in patient I before TGRs insertion (A) and during the period of growing rod lengthening (B). Lateral radiograph before the posterior spinal fusion (C) and at the last follow-up aged 22 years and 3 months (D). The global sagittal balance of the spine is adequate at skeletal maturity but there is proximal junctional kyphosis which developed at the levels above the upper end of the instrumentation and was not progressive; therefore, no fusion extension was required. 
complications with TGRs, as well as the associated physiological, psychological, and socioeconomic effects of multiple anaesthetics and repeat surgeries in children. ${ }^{16-18}$ Other surgical techniques in the treatment of EOS may be categorised as distraction-based (VEPTR and hybrid constructs), utilising growth guidance of the spine (Shilla technique), compression-based (vertebral body tethering), or spinal fusion.

A system of external magnetic distraction of implanted spinal rods was first reported in correcting experimentally induced scoliosis in beagle dogs. ${ }^{19}$ The safety of magnetically controlled growing rods (MCGR) in achieving physiological spinal growth was assessed in a porcine model. ${ }^{20}$ Cheung et al first reported on the effectiveness of MCGRs in 2 patients at 2 years' follow-up with no implant-related complications. ${ }^{21}$ Wick and Konze concurrently reported on the implantation of another MCGR system in 2 patients in North America. ${ }^{22}$

\section{Early Results of MAGEC for EOS}

The MAGEC (MAGnetic Expansion Control; Nuvasive, SanDiego, USA) system is currently the only available MCGR system for the treatment of EOS in Europe and
North America. MAGEC has been licensed in Europe since 2009 and was approved by the FDA in 2017. MAGEC rods are indicated for patients with progressive or severe EOS or those patients who have failed nonoperative treatment (Figures 3 and 4). The aim of MCGR constructs is to control spinal deformity until sufficient spinal and thoracic development has occurred, at which time conversion to definitive spinal fusion is considered. MAGEC is contraindicated for children less than 2 years of age and those allergic to implant materials.

Single or dual MAGEC rod constructs may be used. A detailed description of the key components of MAGEC rods has been previously reported. ${ }^{23}$ It is recommended that the wider actuator section of the MAGEC rod, which cannot be contoured, be placed across the straight thoracolumbar spine. ${ }^{24}$ Proximal and distal fixation is achieved at predetermined foundation levels using pedicle screws, hooks or rib fixation. The implant options available include $4.5 \mathrm{~mm}$ and $5 \mathrm{~mm}$ rod diameters, $70 \mathrm{~mm}$ and $90 \mathrm{~mm}$ rod lengths, and standard or offset rod orientations to permit independent magnetic distraction if dual rods are used. Rods are tunnelled between the upper and lower
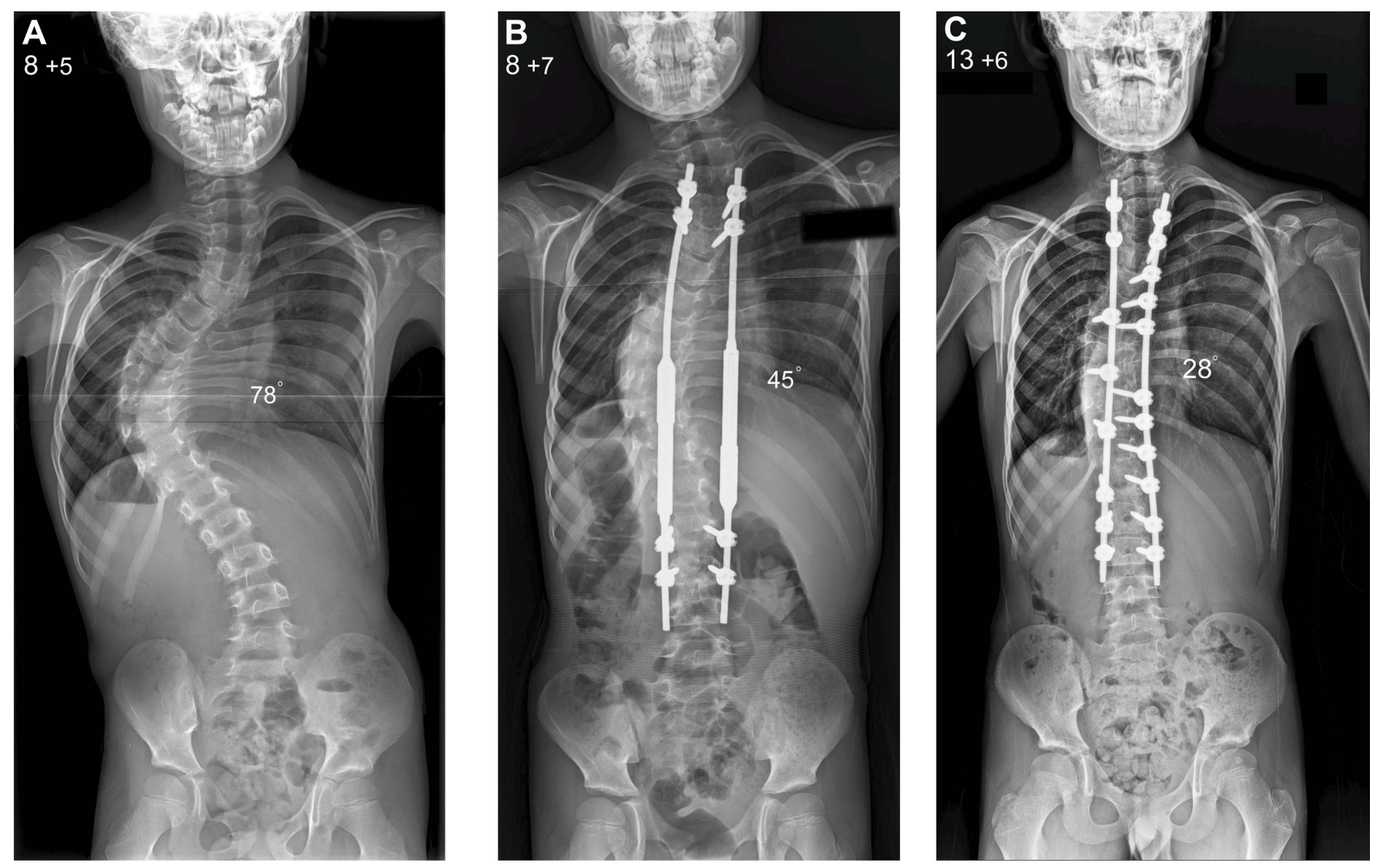

Figure 3 Male patient aged 8 years and 5 months with a progressive infantile idiopathic thoracic scoliosis (patient 2; (A). The patient was treated with the MAGEC and underwent consecutive lengthening at 3-month intervals as part of a clinical visit (B). At age 13 years he underwent the definitive posterior spinal fusion which achieved good coronal balance of the spine $(\mathbf{C})$. 

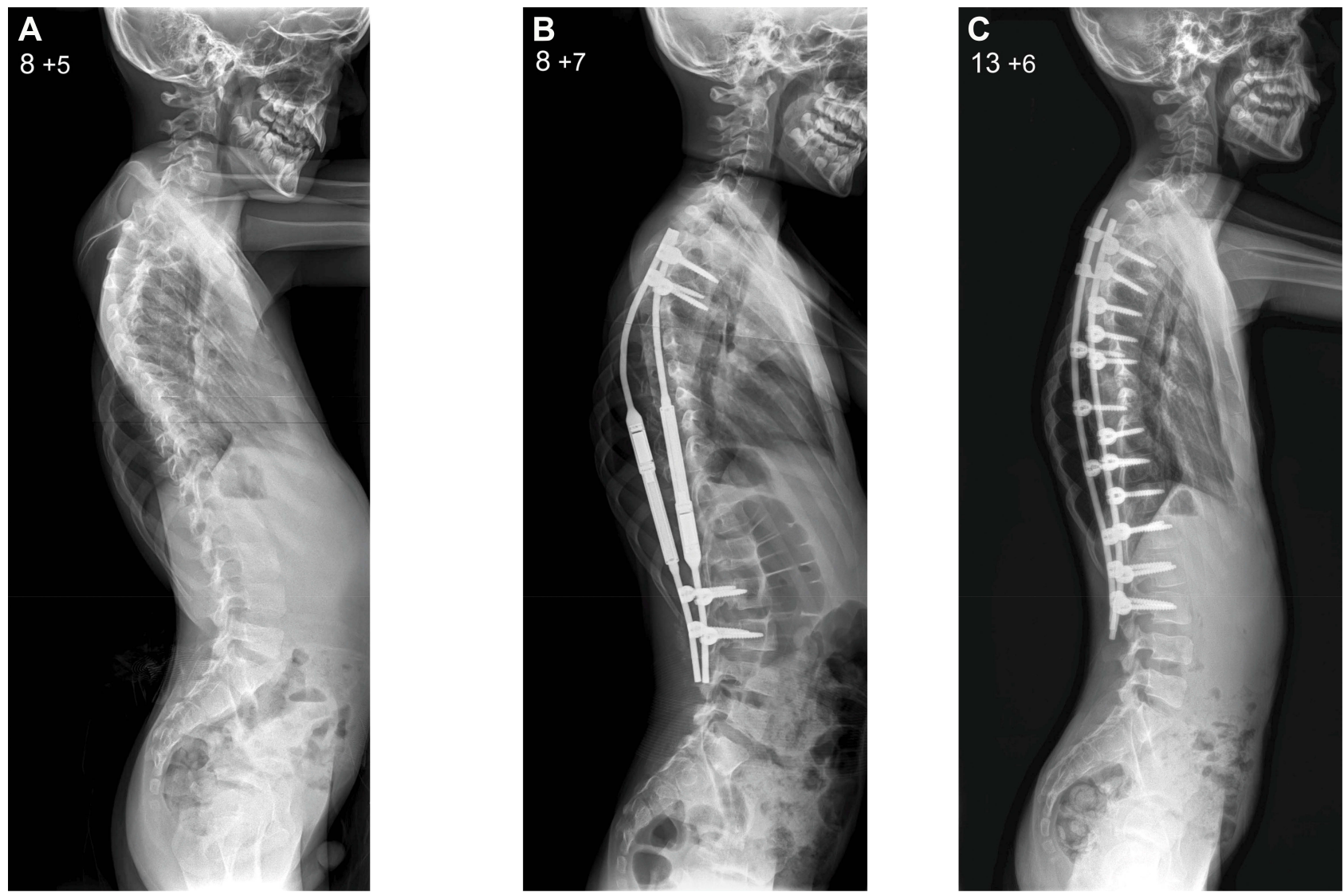

Figure 4 Lateral $x$-rays of the spine in patient 2 before MAGEC placement $(\mathbf{A})$ and during the period of growing rod lengthening $(\mathbf{B})$. Lateral radiograph after the posterior spinal fusion (C) shows proximal junctional kyphosis producing positive global sagittal balance for the spine which has to be kept under monitoring during the period of remaining spinal growth.

foundations and secured to proximal and distal foundations. ${ }^{25}$ Initial lengthening should be performed before final tightening and bone grafting at the proximal and distal foundation levels. ${ }^{24}$ Further distractions are performed non-invasively using an external remote controller. Lengthening can be monitored radiographically or by ultrasound, though interval radiographs are still recommended to monitor for metalware failure. ${ }^{26,27}$ The potential advantages of the MAGEC system have been reported in several clinical studies since the initial case reports describing the use of MCGRs.

In 2013, Dannawi et $\mathrm{al}^{28}$ reported the outcome following the use of MAGEC in 34 children with EOS and mean 15 months' follow-up. Distal fixation was achieved at the neutral vertebra intersected by the central sacral vertical line (CSVL); for neuromuscular patients, the distal instrumentation was extended to the pelvis with iliac bolts. Distractions were performed at intervals of 3 months aiming to achieve $4.5 \mathrm{~mm}$ of distraction on each occasion. Significant improvement in mean Cobb angle was achieved at final follow-up compared to pre-operatively, and dual-rod constructs had significantly greater improvement in Cobb angle compared to the use of a single concave rod. However, mean thoracic kyphosis did not improve across the duration of treatment. The overall complication rate was $18 \%$ including superficial wound infections, rod breakage, fixation failure and prominent metalware, though the duration of follow-up was relatively short. Pulmonary function tests improved by between $14.1 \%$ and $17.2 \%$ following MAGEC treatment in patients with EOS due to neuromuscular disease. ${ }^{29}$

The results of a further 8 patients with EOS treated by MAGEC with follow-up to 28 months were reported by Hickey et al in $2014 .{ }^{30}$ Half of the patients in this cohort underwent MAGEC as a primary procedure (mean age 4.5 years at MAGEC insertion) and half as conversion from TGRs (mean age 10.9 years at MAGEC insertion). Distractions were performed at intervals of 6-8 weeks in an attempt to support physiological spinal growth. The coronal Cobb angle was significantly reduced when 
MCGR was used as a primary procedure with correction maintained at follow-up. The improvement in coronal curvature was also maintained at final follow-up for MAGEC rods inserted as revision procedures. Spinal growth following MAGEC was less than in previous studies and measured at only $60 \%$ of the predicted values; 2 patients experienced loss of distraction, a complication unique to MCGRs. ${ }^{21,28}$

\section{NICE Guidance (20I4)}

In 2014, the National Institute of Health and Care Excellence in the United Kingdom produced recommendations on the clinical and cost-effectiveness of MAGEC for spinal lengthening in children with EOS. ${ }^{31}$ This review compared the reported outcomes following MAGEC with surgical distraction using TGRs. The improvement in Cobb angle across all patients treated by MAGEC was similar to that for TGR $\left(27^{\circ}\right.$ versus $\left.28^{\circ}\right)$. Treatment by MAGEC did not support total spinal height as effectively as reported for TGR (46 mm versus $77 \mathrm{~mm}$ ). The infection rate, number of surgical procedures and rate of device failure across all patients at final follow-up was lower for patients treated by MAGEC than for TGR. However, direct comparisons at final follow-up across all patients in each group may not be appropriate due to the heterogeneity amongst aetiology of EOS, severity of spinal deformity, growing rod constructs and duration of followup of the patients in the included available studies.

Interestingly, when patients treated by MAGEC were compared with a subgroup of patients treated by TGR and similar duration of follow-up, the mean difference in total height between baseline and follow-up was $4.6 \mathrm{~cm}$ with MAGEC and $10.8 \mathrm{~cm}$ for TGRs, the estimated mean number of infective episodes per patient was 0.03 with MAGEC and 0.03 for TGRs, and the annualised rate of device failure was similar at around $4.5 \%$ in both the MAGEC and TGR patient groups. ${ }^{32}$ The NICE review in 2014 also recommended that MAGEC rods are generally cost saving compared to TGRs and that the cost efficiencies are realised during the third year following implantation.

These results indicated that MAGEC may correct and maintain coronal plane deformity in patients with EOS, but that MAGEC is not able to support spinal lengthening as effectively as TGRs. The rate of previously established complications of TGRs was similar following treatment with MAGEC. There was limited data on several other relevant clinical outcomes including pulmonary function, thoracic kyphosis, as well as psychological and satisfaction measures for both patient and caregivers. The 2014 NICE review concluded that there was "neither the quality nor quantity of evidence to draw firm conclusions regarding the clinical efficacy of MAGEC rods compared with conventional growing rods".

\section{MAGEC in Cohort Studies: Clinical and Radiological Results}

Studies reporting longer duration of follow-up and more detailed radiological assessment following use of MAGEC have subsequently been reported. Thompson et $\mathrm{al}^{33}$ reported the outcomes of 19 patients treated by MAGEC with mean 22.4 months' follow-up. They found that MAGEC was able to improve the coronal plane deformity and maintain this correction throughout follow-up (from mean $62^{\circ}$ to $45.1^{\circ}$ ). They also identified that pre-operative thoracic kyphosis did not improve with use of MAGEC (from $49.3^{\circ}$ pre-operatively to $50.1^{\circ}$ at follow-up), and noted an incidence of proximal junctional kyphosis (PJK) of $52.6 \%$ in their cohort. Interestingly, total spinal height was improved with MAGEC, from $288 \mathrm{~mm}$ to $331 \mathrm{~mm}$ at latest follow-up; this was achieved by distracting in accordance with DiMeglio growth charts, rather than distraction until "clunking" occurs. ${ }^{34}$ Patients treated with MAGEC as revision surgery achieved significantly less spinal growth than that seen in patients undergoing MAGEC as a primary procedure. ${ }^{35}$

Similar results were reported by Hosseini et $\mathrm{al}^{36}$ in another cohort of MAGEC patients with a 2-year followup, though they noted a slightly greater initial improvement in scoliosis size and that some patients in whom MAGEC was performed as a revision procedure exhibited a decrease in total spinal height. In the second largest reported series of patients treated by MCGRs, Lebon et $\mathrm{al}^{37}$ identified that MAGEC may correct coronal deformity satisfactorily but can enact little improvement in thoracic or total spinal height. The authors reported a $57 \%$ patient complication rate at mean 18.4 months' follow-up, no overall improvement in thoracic kyphosis and difficulty in distraction in the presence of marked postoperative thoracic kyphosis and when MAGEC was used to treat neuromuscular or syndromic scoliosis.

Teoh et $\mathrm{al}^{38}$ published outcomes in a cohort of EOS patients treated by MAGEC with the longest reported follow-up (8 patients; mean 4-years' follow-up). Five patients received dual-rod and 3 patients single-rod 
MCGRs constructs. Scoliosis improved from mean $60^{\circ}$ preoperatively to $42^{\circ}$ post-operatively. Six (75\%) patients required revision surgery for instrumentation problems or development of PJK; all 3 patients with single-rod constructs required revision. Only 4 patients had MAGEC in situ at 4 years; implant removal occurred at mean 39 months. This first report of medium-term results for MCGR demonstrated a high rate of significant complications and concluded that caution is required in the use of MAGEC for EOS.

A systematic review of the radiological outcomes and clinical complications associated with MAGEC rods was performed by Thakar et $\mathrm{al}^{39}$ comprising 15 studies with 196 patients treated with MAGEC as a primary procedure and 66 patients treated with MAGEC at revision surgery for EOS; mean follow-up was 29.7 months. Improvements were reported between mean preoperative and final follow-up measurements for Cobb angle $\left(64.8^{\circ}\right.$ versus $\left.34.9^{\circ}\right)$, thoracic kyphosis $\left(38^{\circ}\right.$ versus $29.6^{\circ}$ ), pre-op T1-T12 height (174 mm versus $209.4 \mathrm{~mm}$ ) and T1-S1 height (285.4 mm versus $334.9 \mathrm{~mm}$ ). Complications occurred in $44.5 \%$ of the patients; of note, there was a high rate of unplanned revision surgery (33\%), implant failure (11.7\%) and rod or foundation breakage (10.6\%). There was a greater than twofold increase in the rate of rod breakage when single-rod compared to double-rod MAGEC constructs were used. Implant failure was most commonly attributed to rod breakage or loss of distraction. A high rate $(73 \%)$ of overall complications at medium-term follow-up was identified in patients undergoing MAGEC, especially an increased risk of instrumentation problems and a need for unplanned revision surgery $(46.7 \%){ }^{40,41}$ In a recent meta-analysis, there was no significant difference in the change in Cobb angle or incidence of complications between EOS patients treated by MAGEC or TGRs. ${ }^{41}$

The variation reported in true distraction achieved compared to the desired distraction with MAGEC was investigated by Ahmad et $\mathrm{al}^{42}$ Actual distraction with MAGEC had been reported between $33 \%$ and $45.5 \%$ of intended distraction. ${ }^{37,43}$ For TGRs, increased spinal stiffness and spontaneous fusion over the duration of treatment can lead to the "law of diminishing returns" upon repeated lengthenings, whereby repeated lengthenings yield a decrease in the true distraction achieved. ${ }^{44}$ Ahmad et al identified a near linear decrease in distraction over time. ${ }^{42}$ Their analysis also demonstrated that after initial implantation of the MAGEC, there was no significant improvement in the coronal plane deformity during follow-up. The authors suggested that spinal distraction with MAGEC also follows the "law of diminishing returns".

\section{Implant Failure}

There is now a significant body of work investigating the mechanism of loss of distraction and implant failure with the use of MAGEC. Fracture of the actuator pin in dual MAGEC constructs was initially reported in 2 patients; radiographs and ultrasound imaging identified subtle fracture of the actuator pin resulting in loss of distraction. ${ }^{45}$ The authors had used maximal distraction to "clunking" as the non-invasive distraction strategy in these patients. Fracture of MAGEC rods had previously been reported but outwith the central distraction component. At definitive fusion and explantation of the MCGRs, metallosis in the soft tissues surrounding the casing was observed in both patients. Metallosis refers to aseptic fibrosis, local tissue necrosis or loosening of a device due to metal corrosion and release of wear debris. ${ }^{46}$

These findings of device failure (failure of distraction or component breakage) in association with adjacent soft tissue metallosis were confirmed by further case series reports. Teoh et $\mathrm{al}^{47}$ described gross histological findings of 7 MCGRs explanted from patients receiving MAGEC and requiring revision surgery between 2011 and 2015. All rods exhibited abrasive circumferential markings, 6 rods showed metallosis around the actuator, 4 rods were pistoning (nonfunctioning) and 2 rods had fractured. Further findings included significant metal debris comprising mainly titanium metal fragments in the main actuator outer casing, fracture of the locking pin leading to the observed pistoning and a chronic inflammatory cellular infiltrate in the adjacent soft tissues. Panagiotopoulou et $\mathrm{al}^{48}$ reported surface abrasive damage on the extending bar of all 9 explanted MAGEC rods that they examined by micro-CT, mechanical sectioning and scanning electron microscopy. Six MAGEC rods were removed unexpectedly early due to black staining of the skin, swelling or progressive scoliosis. The authors also identified that MAGEC rods with fractured pins had greater wear at the junction of the extending bar compared to explanted rods with an intact distraction mechanism.

Further detailed analysis of the mechanism of failure of MAGEC rods and associated metallosis has been reported in studies by Joyce et $\mathrm{al}^{23}$ and Rushton et $\mathrm{al}^{49,50}$ as part of a UK retrieval analysis project. In a first report of 34 explanted MAGEC rods, abrasive marks on the extending bar and internal titanium wear debris were identified in all explants. Rod diameter was reduced by up to $17 \%$ secondary to 
localised wear. The radial bearing was non-functional in $74 \%$ of the rods while $44 \%$ of the rods had a fractured drive pin. Rushton et $\mathrm{al}^{49}$ described off-axis loading of MAGEC rods leading to asymmetric abrasion, generating the titanium wear debris seen at explant analysis and in adjacent soft tissues. Furthermore, the drive pin is failing due to inability to overcome both the torque from the MAGEC magnet and the additional abrasive frictional force. The MAGEC system has undergone redesigns with previous implant generations termed Modification 1, Modification 2; the current release is termed MAGEC X. This study included both Modification 1 and Modification 2 MAGEC explants.

In a further study, Rushton et $\mathrm{al}^{50}$ assessed the capacity of explanted MAGEC rods to still generate force compared to their intended pre-implantation standard. A bespoke force gauge provided by the MAGEC manufacturer was used to test 45 explants from 25 patients; the majority of these were Modification 2 MAGEC rods. Sixty-four per cent of the rods produced no force and only $22 \%$ of the rods produced force surpassing threshold for clinical use. For TGR, Noordeen et $\mathrm{al}^{51}$ demonstrated that the force required to achieve equal distraction length increases from $142 \mathrm{~N}$ at initial distraction to $608 \mathrm{~N}$ by the 10th lengthening. Increased force required for successful maximum lengthening with TGRs may be related to soft tissue scarring and spinal stiffness, which may not be dependent on the number of lengthenings. The MAGEC manufacturer's required standard for acceptable MAGEC rod functioning was reported as $187 \mathrm{~N}$, substantially lower than the force reported for maximal subsequent lengthenings with TGRs. ${ }^{51}$

In the largest series analysing explanted MAGEC rods, Rushton et $\mathrm{al}^{50}$ examined the achieved in vivo spinal lengthening in a cohort of predominantly Modification 2 MAGEC rods. The mean spinal lengthening achieved in 38 patients with explanted MAGEC rods was $22.1 \mathrm{~mm}$. Spinal growth supported by MAGEC was negatively correlated with patients' age but did not correlate with body mass at time of implantation. The rate of spinal lengthening with MAGEC also negatively correlated with duration of implantation. Furthermore, no functional MAGEC rods with the ability to lengthen were explanted after 35 months of treatment.

\section{Psychological Impact, Cost-Effectiveness and Safety Issues}

In addition to implant failure by loss of distraction or rod breakage, there are several further safety concerns, as well as clinical and economic issues with the use of MAGEC. It has been previously reported that the serum concentration of metal ions including titanium, niobium and aluminium increase following posterior instrumented correction for idiopathic scoliosis. ${ }^{52}$ MCGR constructs are associated with release of titanium, vanadium and possibly aluminium. ${ }^{53}$ Whether the serum concentration of metal ions correlates with the extent of metallosis or implant failure is unknown and the long-term effect in children of raised serum metal ion concentration and local release of titanium debris is currently unclear. MRI compatibility is a potential concern for patients with MCGRs implanted but retrospective reports have indicated no adverse events associated with MRI performed in patients with MCGRs.

Since the initial NICE assessment in 2014, the results of additional longer-term clinical studies have called into question the cost-effectiveness of MAGEC for EOS. The NICE review indicated that the cost-efficiencies associated with MAGEC would be realised after the third year following implantation. ${ }^{31}$ However, the high rate of reported unexpected revision surgery at early and medium-term follow-up, as well as the fact that in explant studies the majority of MAGEC rods implanted for mean 2.7 years were non-functional, raise doubt regarding treatment of EOS with MAGEC becoming cost-efficient after 3 years compared to TGRs. ${ }^{38,39}$ Cost-effectiveness of MAGEC will vary depending upon different healthcare systems. A more recent cost-analysis from Hong Kong has indicated MCGR treatment only becomes cost-efficient in the fourth year of continuous treatment, whereas the most recent cost-analysis from the US estimated cost-neutrality of MAGEC compared to TGR over 6 years of treatment for EOS through to final fusion. ${ }^{54,55}$

There also remains limited evidence regarding the psychological impact or benefit of treating EOS with MCGRs. Doany et al. ${ }^{56}$ reported Early-Onset Scoliosis Questionnaire (EOSQ-24) results for 25 patients treated by TGR and 19 patients treated by MCGR; when controlled for length of follow-up, there was no significant difference in any domains of the EOSQ-24 between patients treated by TGR or MCGR. Another study of 17 patients treated by TGR and 10 patients treated by MCGR both with minimum 2-year follow-up reported no difference in mental ill-health or intelligence scale results between groups. ${ }^{57}$ The non-invasiveness of MCGRs for EOS has not conferred psychological or mental health benefits from the available results. However, the available number of studies included patients and outcome measures are limited in assessing 
the psychological and mental health outcomes following treatment for EOS.

\section{Comparison of MAGEC with Existing Treatments for EOS}

It is also important to review the role of existing treatments for EOS in the context of emerging evidence regarding MAGEC. Mehta ${ }^{8}$ demonstrated that resolution of syndromic or idiopathic scoliosis can be achieved if casting is begun at $15-21$ months of age and curve magnitude is $27-35^{\circ}$. For patients aged $27-34$ months with curve magnitude of $47-53^{\circ}$, control rather than correction of scoliosis may be achieved. In these patients, casting for up to 64 months can prevent or delay surgery by a duration equivalent to 7 TGR lengthenings in those requiring operative intervention. ${ }^{58}$ Casting may therefore be a reasonable option as an alternative or rather as the first treatment step before growing rod surgery in some patients with EOS. Casting can control the deformity and avoid complications associated with growing rods, but patients undergoing growing rod surgery may achieve better curve correction. ${ }^{59}$

TGRs are a well-described and established technique for treating EOS. ${ }^{60}$ Several of the advantages and disadvantages of MAGEC compared to TGRs have already been discussed. MAGEC instrumentation appears to be able to control coronal curvature similar to TGRs for EOS. ${ }^{38,39,61}$ Reduced distraction with repeated lengthenings has been described for both TGRs and MAGEC. ${ }^{62,63}$ Both constructs have very limited ability to control the rotatory (3-dimensional) component of scoliotic deformity. There are few studies comparing outcomes between TGRs and MAGEC for EOS; 2 studies comparing the thoracic and total spinal height growth between TGRs and MAGEC have reported no significant difference between groups. ${ }^{61,64}$ Cohort studies have highlighted that MAGEC does not control thoracic kyphosis and may lead to proximal junctional kyphosis and failure of proximal implant fixation. ${ }^{37,64}$ This is a complication not dissimilar to TGRs as a posteriorly based construct has a kyphogenic effect precipitated by serial rod lengthenings and driving the upper thoracic spine into junctional kyphosis resulting in proximal anchor failure. Loss of distraction can occur with MAGEC, which is also associated with a high rate of revision surgery for implant failure. ${ }^{39-41}$ Explant studies indicate that the in vivo lengthening achieved by MAGEC would be exceeded by treatment with TGR after 2-3 lengthenings, which might occur by $12-18$ months following implantation of TGRs. ${ }^{50}$ Both TGR and MCGR constructs are associated with release of titanium and possibly aluminium, though MCGR constructs may release a higher concentration of metal ions with long-term unknown consequences. ${ }^{53}$ Generation of extensive titanium wear debris and adjacent soft tissue metallosis are specific complications of MAGEC implants related to offset loading.

The Shilla technique was developed by McCarthy et $\mathrm{al}^{65}$ This technique utilises growth guidance of the spine to allow deformity correction. Fusion at the apex of the curve is performed with rods that can slide across the proximal and distal anchor points. There are no studies directly comparing MAGEC and Shilla in the treatment of EOS. Compared to TGRs, Shilla results in fewer surgeries, less spinal growth, less curve correction and similar complication rates. ${ }^{66}$ A modified Shilla technique using unilateral apical convex instrumented compression has recently been reported to safely enact active apical correction and may allow improved scoliosis correction. ${ }^{67}$ The vertical expandable prosthetic titanium rib (VEPTR) is another distraction-based system permitting primarily stabilisation of the hemithorax in children with thoracic insufficiency syndrome and secondary control of scoliosis. ${ }^{68}$ VEPTR can achieve spinal lengthening and curve improvement over serial lengthenings. Hybrid constructs using TGRs with ribs as proximal anchor sites and distal spinal fixation have also been described to preserve more total thoracic growth. ${ }^{69}$ Compression-based techniques have gained recent attention with the development of anterior vertebral body tethering; studies reporting outcomes following vertebral body tethering are ongoing but apply primarily to patients with adolescent idiopathic scoliosis rather than EOS.

\section{Conclusion}

MAGEC is an evolving magnetically controlled growing rod system for the treatment of EOS. MAGEC may correct the coronal component of EOS similar to TGRs but has limitations in achieving spinal growth, as well as controlling sagittal profile and axial rotation. Complications inherent with TGR also occur in patients treated by MAGEC. MAGEC is associated with the generation of significant titanium wear debris related to offset loading and subsequent metallosis, as well as a high rate of implant failure requiring unplanned revision surgery. Until the failure of the distraction mechanism of MAGEC is addressed, EOS may be more safely treated by TGRs. 


\section{Disclosure}

The authors report no conflicts of interest in this work.

\section{References}

1. Yang S, LM A, GJ R, Skaggs DL. Early-onset scoliosis: a review of history, current treatment, and future directions. Pediatrics. 2016;137:1. doi:10.1542/peds.2015-0709

2. Campbell RM Jr., Smith MD. Thoracic insufficiency syndrome and exotic scoliosis. J Bone Joint Surg Am Vol. 2007;89(Suppl 1):108-122. doi:10.2106/JBJS.F.00270

3. Canavese F, Dimeglio A. Normal and abnormal spine and thoracic cage development. World J Orthop. 2013;4(4):167-174. doi:10.5312 wjo.v4.i4.167

4. Campbell RM Jr., Smith MD, Mayes TC, et al. The characteristics of thoracic insufficiency syndrome associated with fused ribs and congenital scoliosis. J Bone Joint Surg Am Vol. 2003;85(3):399-408. doi:10.2106/00004623-200303000-00001

5. Pehrsson K, Larsson S, Oden A, Nachemson A. Long-term follow-up of patients with untreated scoliosis. A study of mortality, causes of death, and symptoms. Spine. 1992;17(9):1091-1096.

6. Baulesh DM, Huh J, Judkins T, Garg S, Miller NH, Erickson MA. The role of serial casting in early-onset scoliosis (EOS). $J$ Pediatr Orthop. 2012;32(7):658-663. doi:10.1097/BPO.0b013e318269c438

7. Waldron SR, Poe-Kochert C, Son-Hing JP, Thompson GH. Early onset scoliosis: the value of serial risser casts. $J$ Pediatr Orthop. 2013;33(8):775-780. doi:10.1097/BPO.0000000000000072

8. Mehta MH. Growth as a corrective force in the early treatment of progressive infantile scoliosis. J Bone Joint Surg Br Vol. 2005;87 (9):1237-1247. doi:10.1302/0301-620X.87B9.16124

9. Demirkiran HG, Bekmez S, Celilov R, Ayvaz M, Dede O, Yazici M. Serial derotational casting in congenital scoliosis as a time-buying strategy. $J$ Pediatr Orthop. 2015;35(1):43-49. doi:10.1097/ BPO.0000000000000229

10. Harrington PR. Scoliosis in the growing spine. Pediatr Clin North Am. 1963;10:225-245. doi:10.1016/S0031-3955(16)31381-5

11. Moe JH, Kharrat K, Winter RB, Cummine JL. Harrington instrumentation without fusion plus external orthotic support for the treatment of difficult curvature problems in young children. Clin Orthop Relat Res. 1984;185:35-45.

12. Blakemore LC, Scoles PV, Poe-Kochert C, Thompson GH. Submuscular Isola rod with or without limited apical fusion in the management of severe spinal deformities in young children: preliminary report. Spine. 2001;26(18):2044-2048. doi:10.1097/ 00007632-200109150-00021

13. Klemme WR, Denis F, Winter RB, Lonstein JW, Koop SE. Spinal instrumentation without fusion for progressive scoliosis in young children. J Pediatr Orthop. 1997;17(6):734-742. doi:10.1097/ 01241398-199711000-00007

14. Tsirikos AI, Loughenbury PR. Single rod instrumentation in patients with scoliosis and co-morbidities: indications and outcomes. World J Orthop. 2018;9(9):138-148. doi:10.5312/wjo.v9.i9.138

15. Akbarnia BA, Breakwell LM, Marks DS, et al. Dual growing rod technique followed for three to eleven years until final fusion: the effect of frequency of lengthening. Spine. 2008;33(9):984-990. doi:10.1097/BRS.0b013e31816c8b4e

16. Bellinger DC, Calderon J. Neurotoxicity of general anesthetics in children: evidence and uncertainties. Curr Opin Pediatr. 2019;31 (2):267-273. doi:10.1097/MOP.0000000000000737

17. Caldas JC, Pais-Ribeiro JL, Carneiro SR. General anesthesia, surgery and hospitalization in children and their effects upon cognitive, academic, emotional and sociobehavioral development - a review. Paediatr Anaesth. 2004;14(11):910-915. doi:10.1111/j.14609592.2004.01350.x
18. Baky FJ, Milbrandt TA, Flick R, Larson AN. Cumulative anesthesia exposure in patients treated for early-onset scoliosis. Spine Deform. 2018;6(6):781-786. doi:10.1016/j.jspd.2018.05.001

19. Takaso M, Moriya H, Kitahara $\mathrm{H}$, et al. New remote-controlled growing-rod spinal instrumentation possibly applicable for scoliosis in young children. $J$ Orthop Sci. 1998;3(6):336-340. doi:10.1007/ s007760050062

20. Akbarnia BA, Mundis GM Jr., Salari P, Yaszay B, Pawelek JB. Innovation in growing rod technique: a study of safety and efficacy of a magnetically controlled growing rod in a porcine model. Spine. 2012;37(13):1109-1114. doi:10.1097/ BRS.0b013e318240ff67

21. Cheung KM, Cheung JP, Samartzis D, et al. Magnetically controlled growing rods for severe spinal curvature in young children: a prospective case series. Lancet. 2012;379(9830):1967-1974. doi:10.1016/S0140-6736(12)60112-3

22. Wick JM, Konze J. A magnetic approach to treating progressive early-onset scoliosis. AORN J. 2012;96(2):163-173. doi:10.1016/j. aorn.2012.05.008

23. Joyce TJ, Smith SL, Rushton PRP, Bowey AJ, Gibson MJ. Analysis of explanted magnetically controlled growing rods from seven UK spinal centers. Spine. 2018;43(1):E16-E22. doi:10.1097/ BRS.0000000000002221

24. Akbarnia A, Mundi G. Magnetically controlled growing rods in early onset scoliosis: indications, timing and treatment. Orthopade. 2019;48:477-485. doi:10.1007/s00132-019-03755-0

25. Munigangaiah S, Brown P, Mohamed M, Bruce CE, Trivedi JM, Davidson NT. A novel technique for the subfascial insertion of magnetically controlled growing rods - The Alder Hey technique. J Craniovertebr Junction Spine. 2018;9(4):250-253. doi:10.4103/ jcvjs.JCVJS_105_18

26. Yoon WW, Chang AC, Tyler P, Butt S, Raniga S, Noordeen H. The use of ultrasound in comparison to radiography in magnetically controlled growth rod lengthening measurement: a prospective study. Eur Spine J. 2015;24(7):1422-1426. doi:10.1007/s00586-014-3589-z

27. Stokes OM, O’Donovan EJ, Samartzis D, Bow CH, Luk KD, Cheung KM. Reducing radiation exposure in early-onset scoliosis surgery patients: novel use of ultrasonography to measure lengthening in magnetically-controlled growing rods. Spine j. 2014;14 (10):2397-2404. doi:10.1016/j.spinee.2014.01.039

28. Dannawi Z, Altaf F, Harshavardhana NS, El Sebaie H, Noordeen H. Early results of a remotely-operated magnetic growth rod in early-onset scoliosis. Bone Joint J. 2013;95-B(1):75-80. doi:10.1302/0301-620X.95B1.29565

29. Yoon WW, Sedra F, Shah S, Wallis C, Muntoni F, Noordeen H. Improvement of pulmonary function in children with early-onset scoliosis using magnetic growth rods. Spine. 2014;39 (15):1196-1202. doi:10.1097/BRS.0000000000000383

30. Hickey BA, Towriss C, Baxter G, et al. Early experience of MAGEC magnetic growing rods in the treatment of early onset scoliosis. Eur Spine J. 2014;23(Suppl 1):S61-S65. doi:10.1007/ s00586-013-3163-0

31. Jenks M, Craig J, Higgins J, et al. The MAGEC system for spinal lengthening in children with scoliosis: a NICE medical technology guidance. Appl Health Econ Health Policy. 2014;12(6):587-599. doi:10.1007/s40258-014-0127-4

32. Wang S, Zhang J, Qiu G, et al. Dual growing rods technique for congenital scoliosis: more than 2 years outcomes: preliminary results of a single center. Spine. 2012;37(26):E1639-E1644. doi:10.1097/ BRS.0b013e318273d6bf

33. Thompson W, Thakar C, Rolton DJ, Wilson-MacDonald J, Nnadi C. The use of magnetically-controlled growing rods to treat children with early-onset scoliosis: early radiological results in 19 children. Bone Joint J. 2016;98-B(9):1240-1247. doi:10.1302/0301620X.98B9.37545 
34. Dahl B, Dragsted C, Ohrt-Nissen S, Andersen T, Gehrchen M. Use of a distraction-to-stall lengthening procedure in magnetically controlled growing rods: a single-center cohort study. J Orthop Surg. 2018;26 (2):2309499018779833. doi:10.1177/2309499018779833

35. Keskinen H, Helenius I, Nnadi C, et al. Preliminary comparison of primary and conversion surgery with magnetically controlled growing rods in children with early onset scoliosis. Eur Spine J. 2016;25 (10):3294-3300. doi:10.1007/s00586-016-4597-y

36. Hosseini P, Pawelek J, Mundis GM, et al. Magnetically controlled growing rods for early-onset scoliosis: a multicenter study of 23 cases with minimum 2 years follow-up. Spine. 2016;41(18):1456-1462. doi:10.1097/BRS.0000000000001561

37. Lebon J, Batailler C, Wargny M, et al. Magnetically controlled growing rod in early onset scoliosis: a 30-case multicenter study. Eur Spine J. 2017;26(6):1567-1576. doi:10.1007/s00586-016-4929-y

38. Teoh KH, Winson DM, James SH, et al. Magnetic controlled growing rods for early-onset scoliosis: a 4-year follow-up. Spine j. 2016;16(4 Suppl):S34-S39. doi:10.1016/j.spinee.2015.12.098

39. Thakar C, Kieser DC, Mardare M, Haleem S, Fairbank J, Nnadi C. Systematic review of the complications associated with magnetically controlled growing rods for the treatment of early onset scoliosis. Eur Spine J. 2018;27(9):2062-2071. doi:10.1007/s00586-018-5590-4

40. Kwan KYH, Alanay A, Yazici M, et al. Unplanned reoperations in magnetically controlled growing rod surgery for early onset scoliosis with a minimum of two-year follow-up. Spine. 2017;42(24):E1410E4. doi:10.1097/BRS.0000000000002297

41. Teoh KH, Winson DM, James SH, et al. Do magnetic growing rods have lower complication rates compared with conventional growing rods? Spine j. 2016;16(4 Suppl):S40-S44. doi:10.1016/j. spinee.2015.12.099

42. Ahmad A, Subramanian T, Panteliadis P, Wilson-Macdonald J, Rothenfluh DA, Nnadi C. Quantifying the "law of diminishing returns' in magnetically controlled growing rods. Bone Joint J. 2017;99-B(12):1658-1664. doi:10.1302/0301-620X.99B12.BJJ2017-0402.R2

43. Rolton D, Thakar C, Wilson-MacDonald J, Nnadi C. Radiological and clinical assessment of the distraction achieved with remotely expandable growing rods in early onset scoliosis. Eur Spine J. 2016;25(10):3371-3376. doi:10.1007/s00586-015-4223-4

44. Sankar WN, Skaggs DL, Yazici M, et al. Lengthening of dual growing rods and the law of diminishing returns. Spine. 2011;36 (10):806-809. doi:10.1097/BRS.0b013e318214d78f

45. Jones CS, Stokes OM, Patel SB, Clarke AJ, Hutton M. Actuator pin fracture in magnetically controlled growing rods: two cases. Spine $J$. 2016;16(4):e287-e291. doi:10.1016/j.spinee.2015.12.020

46. Campbell P, Chun G, Kossovsky N, Amstutz HC. Histological analysis of tissues suggest that 'metallosis' may really be 'plasticosis'. Proc 38th Annu Meeting Orthop Res Soc. 1992;393.

47. Teoh KH, von Ruhland C, Evans SL, et al. Metallosis following implantation of magnetically controlled growing rods in the treatment of scoliosis: a case series. Bone Joint J. 2016;98-B(12):1662-1667. doi:10.1302/0301-620X.98B12.38061

48. Panagiotopoulou VC, Tucker SK, Whittaker RK, et al. Analysing a mechanism of failure in retrieved magnetically controlled spinal rods. Eur Spine J. 2017;26(6):1699-1710. doi:10.1007/s00586-0164936-z

49. Rushton PRP, Smith SL, Forbes L, Bowey AJ, Gibson MJ, Joyce TJ. Force testing of explanted magnetically controlled growing rods. Spine. 2019;44(4):233-239. doi:10.1097/BRS.0000000000002806

50. Rushton PRP, Smith SL, Kandemir G, et al. Spinal lengthening with magnetically controlled growing rods: data from the largest series of explanted devices. Spine. 2019;45:170-176.

51. Noordeen HM, Shah SA, Elsebaie HB, Garrido E, Farooq N, AlMukhtar M. In vivo distraction force and length measurements of growing rods: which factors influence the ability to lengthen? Spine. 2011;36(26):2299-2303. doi:10.1097/BRS.0b013e31821b8e16
52. Cundy TP, Cundy WJ, Antoniou G, Sutherland LM, Freeman BJ, Cundy PJ. Serum titanium, niobium and aluminium levels two years following instrumented spinal fusion in children: does implant surface area predict serum metal ion levels? Eur Spine J. 2014;23 (11):2393-2400. doi:10.1007/s00586-014-3279-x

53. Yilgor C, Efendiyev A, Akbiyik F, et al. Metal ion release during growth-friendly instrumentation for early-onset scoliosis: a preliminary study. Spine Deform. 2018;6(1):48-53. doi:10.1016/j. jspd.2017.06.005

54. Wong CKH, Cheung JPY, Cheung PWH, Lam CLK, Cheung KMC. Traditional growing rod versus magnetically controlled growing rod for treatment of early onset scoliosis: cost analysis from implantation till skeletal maturity. J Orthop Surg. 2017;25(2):2309499017705022. doi: $10.1177 / 2309499017705022$

55. Polly DW Jr., Ackerman SJ, Schneider K, Pawelek JB, Akbarnia BA. Cost analysis of magnetically controlled growing rods compared with traditional growing rods for early-onset scoliosis in the US: an integrated health care delivery system perspective. Clinicoecon Outcomes Res. 2016;8:457-465. doi:10.2147/CEOR.S113633

56. Doany ME, Olgun ZD, Kinikli GI, et al. Health-related quality of life in early-onset scoliosis patients treated surgically: EOSQ scores in traditional growing rod versus magnetically controlled growing rods. Spine. 2018;43(2):148-153. doi:10.1097/BRS.000000000002274

57. Aslan C, Olgun ZD, Ayik G, et al. Does decreased surgical stress really improve the psychosocial health of early-onset scoliosis patients? A comparison of traditional growing rods and magnetically-controlled growing rods patients reveals disappointing results. Spine. 2019;44(11):E656-E663. doi:10.1097/ BRS.0000000000002938

58. Fletcher ND, McClung A, Rathjen KE, Denning JR, Browne R, Johnston CE 3rd. Serial casting as a delay tactic in the treatment of moderate-to-severe early-onset scoliosis. J Pediatr Orthop. 2012;32 (7):664-671. doi:10.1097/BPO.0b013e31824bdb55

59. Johnston CE, McClung AM, Thompson GH, Poe-Kochert C, Sanders JO; Growing Spine Study G. Comparison of growing rod instrumentation versus serial cast treatment for early-onset scoliosis. Spine Deform. 2013;1(5):339-342. doi:10.1016/j.jspd.2013.05.006

60. Choudhury Z, Tsirikos AI, Marks DS. Early-onset scoliosis - presentation, assessment and treatment options. Orthop Trauma. 2017;31 (6):357-363. doi:10.1016/j.mporth.2017.09.006

61. Akbarnia BA, Pawelek JB, Cheung KM, et al. Traditional growing rods versus magnetically controlled growing rods for the surgical treatment of early-onset scoliosis: a case-matched 2-year study. Spine Deform. 2014;2(6):493-497. doi:10.1016/j.jspd.2014.09.050

62. Agarwal A, Goswami A, Vijayaraghavan GP, et al. Quantitative characteristics of consecutive lengthening episodes in early-onset scoliosis (EOS) patients with dual growth rods. Spine. 2019;44 (6):397-403. doi:10.1097/BRS.0000000000002835

63. Beaven A, Gardner AC, Marks DS, Mehta JS, Newton-Ede M, Spilsbury JB. Magnetically controlled growing rods: the experience of mechanical failure from a single center consecutive series of 28 children with a minimum follow-up of 2 years. Asian Spine J. 2018;12(5):794-802. doi:10.31616/asj.2018.12.5.794

64. Erdogan S, Polat B, Atici Y, Ozyalvac ON, Ozturk C. Comparison of the Effects of magnetically controlled growing rod and traditional growing rod techniques on the sagittal plane in the treatment of early-onset scoliosis. J Korean Neurosurg Soc. 2019;62(5):577-585. doi:10.3340/jkns.2019.0094

65. McCarthy RE, Luhmann S, Lenke L, McCullough FL. The Shilla growth guidance technique for early-onset spinal deformities at 2-year follow-up: a preliminary report. J Pediatr Orthop. 2014;34 (1):1-7. doi:10.1097/BPO.0b013e31829f92dc

66. Andras LM, Joiner ER, McCarthy RE, et al. Growing rods versus Shilla growth guidance: better Cobb angle correction and T1-S1 Length increase but more surgeries. Spine Deform. 2015;3 (3):246-252. doi:10.1016/j.jspd.2014.11.005 
67. Agarwal A, Aker A, Ahmad A. Active apex correction with guided growth technique for controlling spinal deformity in growing children: a modified SHILLA technique. Global Spine J. 2019; e-pub:1-5.

68. Campbell RM Jr. VEPTR: past experience and the future of VEPTR principles. Eur Spine J. 2013;22(Suppl 2):S106-S117. doi:10.1007/ s00586-013-2671-2
69. Yamaguchi KT Jr., Skaggs DL, Mansour S, et al. Are rib versus spine anchors protective against breakage of growing rods? Spine Deform. 2014;2(6):489-492. doi:10.1016/j.jspd.2014.08.007

\section{Publish your work in this journal}

Medical Devices: Evidence and Research is an international, peerreviewed, open access journal that focuses on the evidence, technology, research, and expert opinion supporting the use and application of medical devices in the diagnosis, monitoring, treatment and management of clinical conditions and physiological processes. The identification of novel devices and optimal use of existing devices which will lead to improved clinical outcomes and more effective patient management and safety is a key feature of the journal. The manuscript management system is completely online and includes a very quick and fair peer-review system. Visit http:// www.dovepress.com/testimonials.php to read real quotes from published authors. 